\title{
Jet Lag Type Circadian Rhythm Sleep Disorder
}

National Cancer Institute

\section{Source}

National Cancer Institute. Jet Lag Type Circadian Rhythm Sleep Disorder. NCI Thesaurus.

Code C95074.

A subtype of circadian rhythm sleep disorder in which the individual exhibits an

endogenous pattern of sleep and wakefulness that comes into conflict with the pattern

of sleep and wakefulness required by a new time zone. 